\section{Scanning the brain for answers about effectiveness of graphic warning labels}

\author{
Mark L Rubinstein
}

We know that smokers who perceive greater risks to their health from smoking are more likely to quit. ${ }^{1}$ Thus, while 'traditional' cigarette pack imagery helps to reinforce cigarette advertising and promote purchasing behaviour, ${ }^{2}{ }^{3}$ graphic warning labels (GWLs) may serve as a form of 'reverse' advertising-increasing smokers' knowledge about the risks associated with smoking and promoting behavioural change by preventing smoking initiation and fostering cessation. ${ }^{4-6}$ In fact, as a smoking cessation and prevention intervention, GWLs are particularly valuable since they are located directly on the product and delivered at the point of use. Moreover, if smoking is associated with a lapse of judgment and temporary disregarding of health consequences, messaging by highlighting the risk of smoking coincident with use may be most beneficial. ${ }^{78}$

While there remains some controversy around the effectiveness of GWLs across populations, studies of their relative effectiveness show a decrease in intention to smoke among never and experimental smokers, ${ }^{9}$ and an increase in intention to quit among experimental and established smokers after viewing the GWLs. ${ }^{10}$ This argument is further supported by the finding that GWLs are more effective in influencing antismoking intentions and behaviours compared with the less emotion provoking, text-only messaging found on current cigarette packaging. ${ }^{11-13}$ Consequently, use of GWLs is recommended by the WHO. Unfortunately, despite efforts by the US Congress to mandate such warning labels, ${ }^{14}$ implementation has been suspended by legal actions on behalf of the tobacco companies. Specifically, tobacco companies have argued that GWLs do not provide information to the smoker, but rather evoke 'negative emotions'. The neurobiological underpinnings for the antismoking efficacy of GWLs are still being elucidated. However, it may be the provocation of high emotions which help form the basis for behavioural change. ${ }^{15}$

Correspondence to Mark L Rubinstein, Department of Pediatrics, UCSF, 3333 California Street suite 245, San Francisco, CA 94118, USA; RubinsteinM@peds. ucsf.edu
Studies have documented strong relationships between self-reported arousal and neural responses as measured by functional MRI (fMRI), ${ }^{16}$ and strongly emotional stimuli have been linked to memory encoding and retrieval (likely through an interaction between the amygdala and hippocampus). ${ }^{17-19}$ These findings have particular relevance for GWLs since emotional antismoking visual stimuli have been shown to produce activation in similar regions of the brain (eg, the amygdala), ${ }^{20-22}$ and this activation is associated with quitting smoking. ${ }^{23}$

In the accompanying manuscript, Wang et al used fMRI to further investigate the neurobiological basis for the efficacy of GWLs in adult daily smokers. Specifically, they compared the levels of brain activation and self-reported urge to smoke produced by GWLs, rated either high or low on an emotional reaction (ER) scale. The authors reported that GWLs with the highest ER ratings produced greater neural activation in brain regions associated with emotional memory, including the amygdala, hippocampus and insula, compared with the low ER GWLs. Supporting prior research on memory formation and emotion, they also reported that this increased activation coincided with greater image recall. More importantly, they found that the higher ER GWLs produced a greater reduction in the craving to smoke. Taken together, these findings provide further support for the idea that it is the strong emotional response that drives the behavioural impact from GWLs.

Relevant limitations noted by the authors include the fact that non-daily and non-smokers were excluded from study and they suggest that future studies include these important groups. Although smokers may be the main target audience for GWLs, an evaluation of the neurobehavioural responses to GWLs in nonsmokers and adolescents, in particular, would provide further information on their ability to inhibit intention to smoke or smoking initiation. Importantly, the authors also call for longitudinal studies to evaluate the effects of different GWLs on behavioural change.

This study adds to the growing list of literature on GWLs by providing support for the utility of these important healthmessaging tools and offers further support for the relevant regulatory bodies in their antismoking efforts. Further, understanding how the brain responds to different GWLs can also help inform the development of more effective types of visual messaging in the future.

Competing interests None.

Provenance and peer review Commissioned; internally peer reviewed.

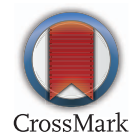

To cite Rubinstein ML. Tob Control 2015;24:211212.

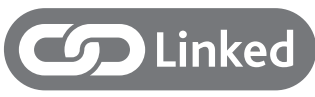

- http://dx.doi.org/10.1136/tobaccocontrol-2014051993

Tob Control 2015;24:211-212.

doi:10.1136/tobaccocontrol-2014-052205

\section{REFERENCES}

1 Romer D, Jamieson P. Do adolescents appreciate the risks of smoking? Evidence from a national survey. $J$ Adolesc Health 2001;29:12-21.

2 Wakefield $M$, Letcher T. My pack is cuter than your pack. Tob Control 2002;11:154-6.

3 Wakefield M, Morley C, Horan JK, et al. The cigarette pack as image: new evidence from tobacco industry documents. Tob Control 2002;11(Suppl 1): 173-80.

4 Hammond D, Fong GT, McDonald PW, et al. Showing leads to doing: graphic cigarette warning labels are an effective public health policy. Eur J Public Health 2006;16:223-4; author reply 225.

5 Hammond D, Fong GT, McNeill A, et al. Effectiveness of cigarette warning labels in informing smokers about the risks of smoking: findings from the International Tobacco Control (ITC) Four Country Survey. Tob Control 2006;15(Suppl 3):iii19-25.

6 Azagba S, Sharaf MF. The effect of graphic cigarette warning labels on smoking behavior: evidence from the Canadian experience. Nicotine Tob Res 2013;15:708-17.

7 Stillwell DJ, Tunney RJ. Effects of measurement methods on the relationship between smoking and delay reward discounting. Addiction 2012;107:1003-12.

8 Heyman GM. Addiction and choice: theory and new data. Front Psychiatry 2013;4:31.

9 Moodie C, Mackintosh AM, Hastings G. Adolescents response to pictorial warnings on the reverse panel of cigarette packs: a repeat cross-sectional study. Tob Control 2015;24:e93-7.

10 Hammond D, Fong GT, McDonald PW, et al. Impact of the graphic Canadian warning labels on adult smoking behaviour. Tob Control 2003;12:391-5.

11 Borland R, Wilson N, Fong GT, et al. Impact of graphic and text warnings on cigarette packs: findings from four countries over five years. Tob Control 2009;18:358-64.

12 Fong GT, Hammond D, Hitchman SC. The impact of pictures on the effectiveness of tobacco warnings. Bull World Health Organ 2009;87:640-3.

13 Kees J, Burton S, Andrews J, et al. Tests of graphic visuals and cigarette package warning combinations: 


\section{Editorial}

implications for the framework convention on tobacco control. J Public Policy Market 2006;25:212-23.

14 Food, Drug Administration HHS. Required warnings for cigarette packages and advertisements. Final rule. Fed Regist 2011;76:36628-777.

15 Wang AL, Lowen SB, Romer D, et al. Emotional reaction facilitates the brain and behavioural impact of graphic cigarette warning labels in smokers. Tob Control 2015;24:217-24.

16 Newman-Norlund RD, Thrasher JF, Fridriksson J, et al. Neural biomarkers for assessing different types of imagery in pictorial health warning labels for cigarette packaging: a cross-sectional study. BMJ Open 2014;4:e06411.

17 Mickley KR, Kensinger EA. Emotional valence influences the neural correlates associated with remembering and knowing. Cogn Affect Behav Neurosci 2008;8:143-52.

18 LaBar KS, Cabeza R. Cognitive neuroscience of emotional memory. Nat Rev Neurosci 2006;7: 54-64.

19 Dolcos F, LaBar KS, Cabeza R. Interaction between the amygdala and the medial temporal lobe memory system predicts better memory for emotional events. Neuron 2004;42:855-63.
20 Phelps EA, LeDoux JE. Contributions of the amygdala to emotion processing: from animal models to human behavior. Neuron 2005;48:

175-87.

21 Zald DH. The human amygdala and the emotional evaluation of sensory stimuli. Brain Res Brain Res Rev 2003;41:88-123.

22 LeDoux J. The emotional brain, fear, and the amygdala. Cell Mol Neurobiol 2003;23:727-38.

23 Jasinska AJ, Chua HF, Ho SS, et al. Amygdala response to smoking-cessation messages mediates the effects of serotonin transporter gene variation on quitting. Neuroimage 2012;60:766-73. 